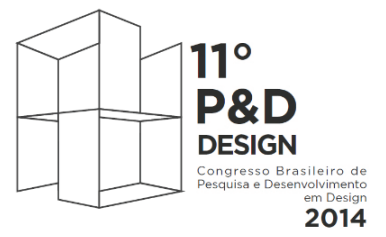

\title{
O EBOOK INFANTIL E AS RELAÇÕES TEXTO-IMAGEM-INTERAÇÃO
}

\author{
Andréa Bellotti de Souza Lima \\ Mestranda, Escola Superior de Desenho Industrial/Universidade do Estado \\ do Rio de Janeiro \\ andrea.bellotti07@gmail.com \\ Washington Dias Lessa \\ Doutor, Escola Superior de Desenho Industrial/Universidade do Estado \\ do Rio de Janeiro \\ washington.lessa@gmail.com
}

\begin{abstract}
Resumo: Este artigo visa investigar o ebook infantil para tablet com base numa primeira aproximação da reflexão de Sophie Van der Linden sobre o livro impresso ilustrado. Elegendo algumas das categorias de análise propostas pela autora, buscou-se compreender e caracterizar como estas se manifestam, tendo em vista a interação, no âmbito do ebook para crianças. O corpus para essa demonstração foi estabelecido a partir de uma seleção de ebooks de literatura infantil reconhecidos pela qualidade de sua realização. Esta adequação de categorias analíticas ao artefato interativo pretende contribuir para a compreensão das questões de design que se fazem presentes na produção dos livros digitais para crianças.
\end{abstract}

Palavras-chave: design, ebook infantil, categorias

Abstract: This article aims to investigate the children's ebook based on Sophie van der Linden's reflections on the picture book. Having elected certain categories of analysis proposed by the author, we sought to understand and characterize how these categories manifest themselves considering the interaction within the ebook for children. The corpus for this demonstration was established from a selection of ebooks for children's literature recognized by the quality of its realization. The suitability of the analytical categories to the interactive artifact aims to contribute to the understanding of the design issues that are present in the production of digital books for children.

Keywords: design, children's ebook, categories

\section{INTRODUÇÃO}

De acordo com Richard Hendel, "o trabalho real de um designer de livros não é fazer as coisas parecerem 'legais', diferentes ou bonitinhas. É descobrir como colocar uma letra ao lado da outra de modo que as palavras do autor de modo que as palavras 
pareçam saltar da página" (2003, p. 3), ou seja, descobrir diferentes caminhos para destacar da melhor maneira a palavra do autor. O presente artigo busca contribuir para uma investigação desses caminhos no que tange ao livro digital infantil para tablet, levando em consideração que, em se tratando de livros infantis, as "palavras do autor" podem ser imagens. A experiência da leitura é mais do que a decodificação do texto ou a recepção passiva da narrativa, e, nos livros infantis ilustrados, o grande desafio é fazer com que as relações entre texto, imagem e suporte possibilitem uma leitura integrada. A opção metodológica foi a de recorrer a uma pesquisa sobre o design da literatura infantil impressa. A partir de algumas das categorias propostas por Sophie Van der Linden em seu livro Para Ler o Livro Ilustrado, foi investigada a sua adequação ao livro infantil interativo.

Van der Linden define como livros ilustrados aquelas "obras em que a imagem é especialmente preponderante em relação ao texto, que, aliás, pode estar ausente. A narrativa se faz de maneira articulada entre texto e imagem" (Van der Linden, 2011, p. 24). Nesse trabalho a autora aborda um conjunto de livros selecionados entre a produção contemporânea de editoras francesas e desenvolve sua investigação recorrendo a diferentes categorias de análise.

Apesar do livro ilustrado e do ebook infantil serem produtos diferentes, em ambos o tipo de literatura é o mesmo - texto reduzido e imagem como elemento importante-, e isso faz com que seja possível tentar compreender o ebook infantil a partir da reflexão de Van der Linden. De seu livro, na seção "Páginas e Espaços do Livro" (pp.64-87), foram escolhidos alguns conceitos que se referem ao que a autora denomina funcionamento do livro ilustrado (p.86); assim como foram escolhidas na seção "Textos e Imagens" (pp.88-135) categorias referentes a aspectos narrativos.

Os ebooks selecionados para este estudo - produzidos a partir de 2010, ano de lançamento do iPad - são, em sua maioria, vencedores de prêmios internacionais ou tiveram uma repercussão ampla e positiva na mídia. Com exceção de Alice in Wonderland, Cinderella Sinpinderella e Jack and the Beanstalk, a maioria foi concebida como ebook e não tem versão impressa. Diferente de todos os livros selecionados, What does the Fox say? tem sua origem em uma música e também apresenta uma versão impressa.

No item 2 do artigo, são identificados os tipos de ebooks infantis atualmente produzidos. A seguir, no item 3 , é focalizado como a interação traz um novo dinamismo a aspectos estruturais da relação texto-imagem e, no item 4, como isso pode se dar em relação a aspectos narrativos. $O$ item 5 traz as considerações finais.

\section{UMA NOVA EXPERIÊNCIA DE LEITURA}

Entre as diferenças do ebook em relação ao livro impresso, destaca-se a interação, que possibilita buscas, anotações, gravação de áudio, entre outros recursos. Interessanos aqui focalizar como ela ocorre no ebook infantil, que normalmente envolve a relação texto-imagem. Para isso, partimos da classificação proposta por Junko Yokota em seu artigo Picture Books and the digital world: Educators Making Informed Choices (2014, p. $2,3)$. Nesse artigo, Yokota descreve modelos que correspondem ao desenvolvimento do livro ilustrado digital:

1. Livros ilustrados escaneados: o livro impresso é inteiramente escaneado, conservando seu layout original e mantendo formato do livro, capa, guarda, folha de rosto, páginas duplas, ilustrações e fontes. Nada é adicionado ou subtraído. 
2. Livros ilustrados transformados em "animações": uma extensão da animação em CD-ROM para a tela do computador. O ebook apresenta as ilustrações com movimentos e utiliza recursos cinematográficos como zoom, planos de cena, cortes e transições, além de sons relacionados ao contexto da história. Com o mouse, a criança transita pelas páginas do livro e ativa a narração.

3. Ebooks com recursos únicos do universo digital: mantendo o layout básico do livro impresso, o ebook incorpora recursos digitais como trilha sonora, movimentos, hotspots (determinados elementos da ilustração são programados para responder ao clique do mouse ou ao mouseover), narração (reading aloud); a tipografia é alterada e a localização do texto modificada.

Segundo Yokota, mais recentemente, o advento dos sistemas operacionais iOS e Android possibilitaram o aprimoramento dos ebooks infantis adicionando outros recursos interativos, inclusive, oferecendo a opção de um jogo inserido na narrativa.

4. Ebooks com recursos interativos, incluindo jogos, que expandem a história: ebooks com recursos suplementares que a criança pode acessar; são jogos, possibilidades de desenhar, colorir e outros possíveis desdobramentos da narrativa sempre dentro do contexto da história.

Entendemos que os ebooks analisados neste artigo pertencem às duas últimas categorias de Yokota e podem ser identificados como Appbooks. Como sugere a denominação, são aplicativos, e portanto dependem de um sistema operacional iOS ou Android. O AppBook permite o desenvolvimento de recursos que outros formatos (Mobipocket, KF8, ePub, ePub2, ePub3, ePib, iBooks Author e PDF) não permitem.

Os ebooks que incorporam texto, ilustração e recursos interativos são, com frequência, vistos como equivalentes dos livros ilustrados. Porém é necessário deixar claro que um livro digital é fundamentalmente diferente de um livro impresso. Essa diferença se dá não só na materialidade do suporte, mas também na experiência de leitura.

De modo bastante simplificado, podemos entender um livro digital como o resultado da soma de características da mídia impressa com a mídia digital. Assim, alguns parâmetros utilizados para o desenvolvimento de conteúdo virtual e outros usados para a construção da mídia impressa podem ser adaptados para o desenvolvimento de ebooks.

No artigo Profissionalização do designer de ebooks, a autora Danusa de Oliveira constata que o designer de livros irá transitar entre a linguagem gráfica da tradição impressa e os códigos visuais da web, conformando novas estratégias no desenvolvimento de ebooks.

\section{CATEGORIAS REFERENTES ÀS RELAÇÕES ESTRUTURAIS ENTRE TEXTO E IMAGEM}

Van der Linden aborda o funcionamento interno do livro ilustrado no capítulo "Páginas e espaços do livro" (p. 64), e dele destacamos os seguintes aspectos estruturais; tipos de diagramação, variações de diagramação, enquadramento, desenquadramento, campo e extracampo, montagem e junção. 


\subsection{Tipos de diagramação}

\section{Dissociação}

A diagramação dissociativa é caracterizada pela alternância página de texto e página com imagens. No livro impresso, a imagem ocupa a "página nobre", e o texto, na página esquerda, geralmente é impresso em um fundo homogêneo. A separação máxima entre texto e imagem, materializada pela dobra do livro, faz com que o leitor alterne entre observação da imagem e leitura de texto num ritmo lento de leitura. No ebook, geralmente, não existe essa diferenciação de páginas. O mais lógico é a exibição da página simples, mas há casos em que o par de páginas pode ser exibido e o ebook oferece essa opção de layout, denominado flowable layout. ${ }^{1}$

O formato mais comum para ebook infantil é o fixo (fixed layout ${ }^{2}$ ), pois ele permite maior controle dos elementos da página e da diagramação. Quando o ebook reproduz exatamente o par de páginas do livro impresso exibindo a marca da dobra e mimetizando o passar de páginas, a diagramação dissociativa acontece tal qual no impresso. Os ebooks que descartam a reprodução da página dupla e utilizam a diagramação dissociativa apresentam a possibilidade do pequeno leitor habilitar ou desabilitar o texto ao tocar em determinado ponto da tela. Dessa forma, ocorre a separação máxima entre texto e imagem, tornando o ritmo de leitura mais lento, e o texto não interfere visualmente na ilustração.

O ebook Moster's Socks conta a história de um monstro chamado Monster que procura suas meias perdidas e, no desenrolar da história, outros personagens Ihe indicam que caminho seguir. Este Appbook de layout fixo não tem versão impressa e ganhou o terceiro lugar no Bologna Ragazzi Digital Awards 2013. Monster's Socks é um ebook que utiliza uma diagramação dissociativa possível apenas no livro digital: o personagem principal, ao caminhar, sempre comandado pelo leitor, pisa em pontos demarcados no chão que habilitam e desabilitam o texto.
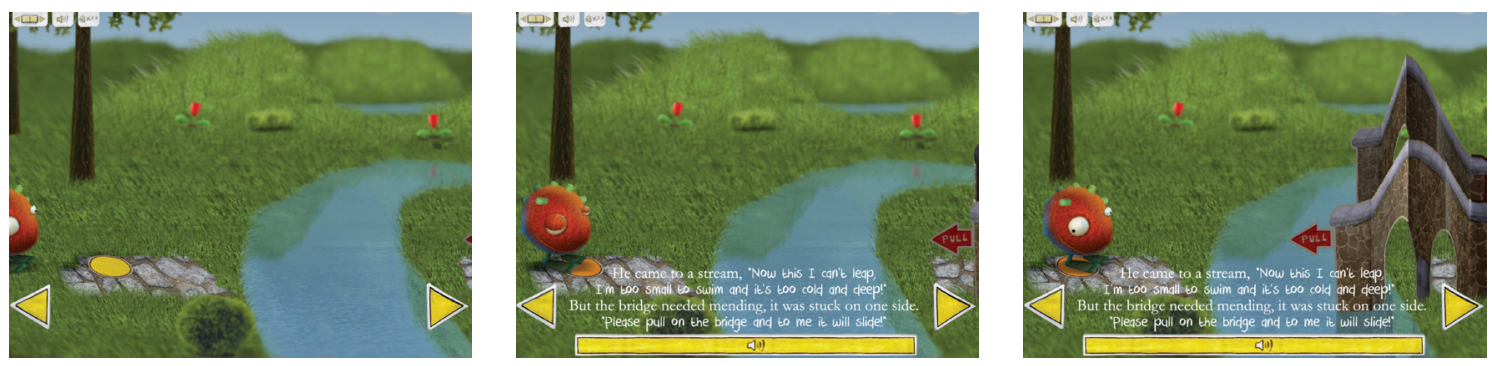

Figura 1 - Ebook Monster's Socks. Separação máxima entre texto e imagem.

\section{Associação}

É a diagramação mais comum do livro ilustrado, reunindo pelo menos um enunciado verbal e um enunciado visual na mesma página. Texto e imagem podem ser organizados de diversas maneiras na página ou na página dupla, e essas diferentes estruturas terão implicações diversas, dependendo da intenção narrativa.

No ebook, a diagramação associativa pode ocorrer de modo estático, exatamente como num livro impresso, mas esse não é o caso do ebook Four Little Corners que utiliza uma diagramação associativa. Vencedor do Bologna Ragazzi Digital Award 2013, conta a

1. Flowable Layout (ou Layout de formato fluido); esses arquivos tem a capacidade de redimensionar o layout e o corpo da fonte de acordo com o suporte e preferências de leitura.

2. Fixed layout (ou layout de formato fixo); não permite redimensionamento de layout ou corpo de fonte. Formato geralmente mais usado em ebooks infantis por permitir maior controle operacional. 
história de um quadrado que não consegue passar pela mesma porta pela qual passam seus amigos redondos. Sua narrativa se sustenta em uma pequena diversidade de reações ao toque na tela, animações e sons. É um Appbook de layout fixo e apresenta texto, imagens animadas, interação e narração. Em sua diagramação associativa o texto aparece de uma maneira interessante, pois é utilizado o recurso de fade out escurecimento gradual da cor do texto -, junto com a imagem ao mudarmos de tela.
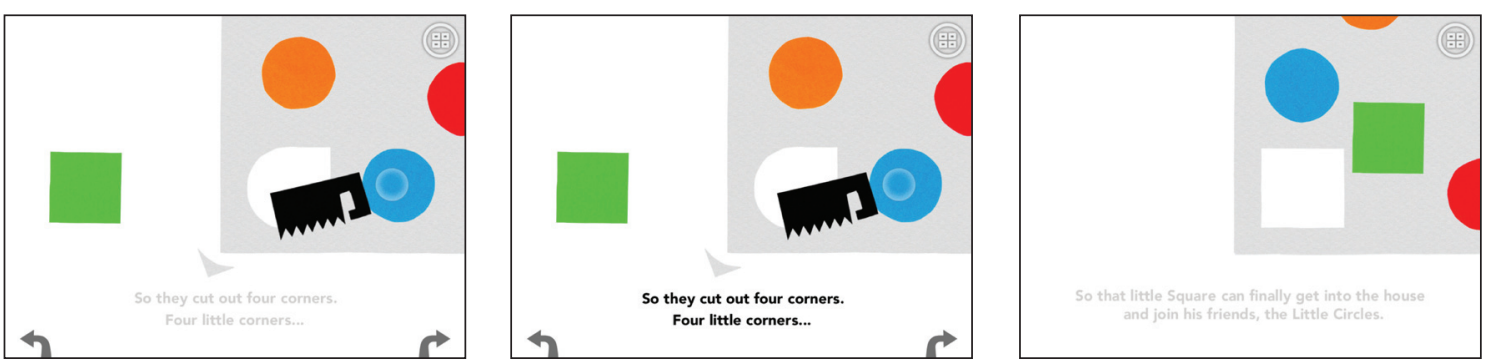

Figura 2 - Ebook For Little Corners com efeito fade out no texto.

\section{Conjunção}

Texto e imagens se encontram organizados em uma composição geral. Se diferencia da diagramação associativa porque apresenta vários enunciados que denotam muito mais uma contiguidade do que uma continuidade. Texto e imagem estão integrados, enquanto que, na diagramação associativa, as mensagens tendem a ser percebidas separadamente.

O ebook What does the Fox say? tem versão impressa e é resultado da ilustração de uma letra de música. O clipe da música, que leva o mesmo nome do livro, teve uma grande repercussão nas mídias de comunicação e também nas mídias sociais. Segundo o site de notícias $\mathrm{G}^{3}$, foi um dos vídeos mais acessados de 2013, com 276 milhões de visualizações.

Este ebook utiliza a conjunção para conduzir a criança pela sucessão dos sons emitidos por uma série de animais, estando sempre presente a incógnita de qual seria o som emitido pela raposa. A tipografia está integrada à ilustração, pois a disposição da massa de texto no espaço da página se adequa às ilustrações sem uma diagramação padronizada, o que torna difícil isolar texto de imagem. Dessa forma, a própria narrativa é questionada, já que este tipo de diagramação favorece uma exploração mais livre das mensagens, ou seja, o leitor é quem decide a sequência de leitura; uma leitura não linear.
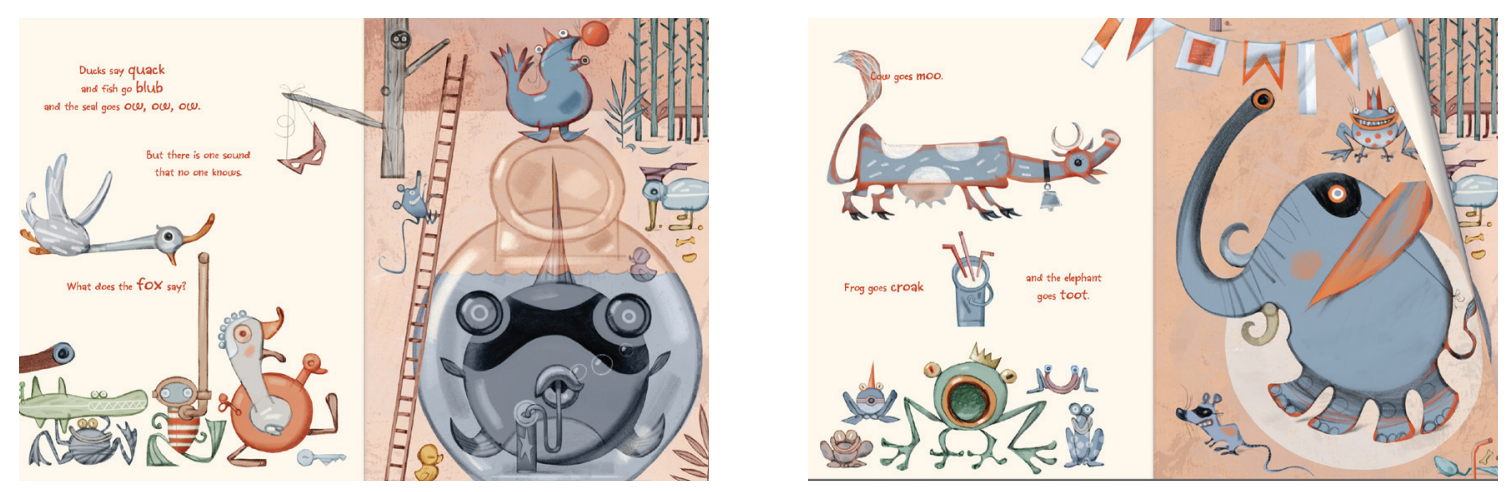

Figura 3 - Ebook What Does the Fox Say? Texto organizado em composição com a imagem.

3. http://g1.com/ acesso em 11 de abril de 2014. 


\subsection{Variações de diagramação}

Van der Linden aponta que o livro ilustrado contemporâneo se caracteriza por uma grande liberdade formal de diagramação. Dentro de uma mesma obra, pode-se encontrar variações na organização da página. Os ebooks de flowable layout não são muito frequentes na produção de ebooks infantis, mas existem. Esse formato permite que a diagramação do livro seja alterada a qualquer momento.

Cinderella Spinderella, vencedor do The Digital Book Awards (em 2014) na categoria e-book flowable, conta uma história baseada no clássico do escritor francês Charles Perrault, Cinderela. Com algumas modificações da personagem principal, a ideia geral da história continua a mesma. É um projeto pensado especificamente para ebook. Esse appbook segue a orientação do suporte e oferece algumas opções de tipografia, corpo de fonte e cor de fundo. O leitor decide o layout que mais lhe agrada. Seu conteúdo e diagramação se adaptam às diferentes orientações, indicando que a equipe pensou em variações da organização da página.
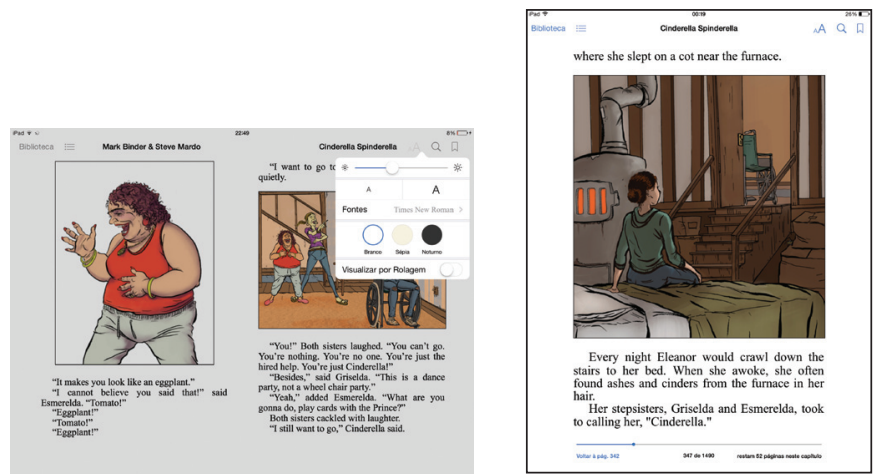

Figura 4 - Ebook Cinderella Spinderella. Diagramação redimensionável.

\subsection{Enquadramento, Desenquadramento, Campo e Extracampo}

Um enquadramento de cima para baixo (plongée), de baixo para cima (contraplongée) ou um enquadramento oblíquo, que passa uma sensação de instabilidade, acarretam implicações específicas num livro ilustrado. Ao enquadrar o personagem principal (ou outro elemento qualquer) ou desenquadrá-lo (removê-lo da posição central), evidencia-se campo e extracampo, ou seja, ao determinarmos um enquadramento, estamos determinando tanto aquilo que está dentro do nosso campo de visão quanto o que está fora dele. Para além dos limites do enquadramento, outro espaço nos é sugerido.

Essas são noções que surgiram com o cinema e acabaram designando também a cena representada na ilustração. No livro impresso esses pontos de vista são representados estaticamente, sendo desenvolvidos página a página, ao passo que no ebook pode-se de fato simular o movimento de câmera.

Integrando a lista Top 25 do site Overlapps.com, The Very Cranky Bear (2012) conta a história de três amigos que, ao tentarem se abrigar da chuva em uma caverna, encontram um urso bastante irritado. O ebook se apropria dessa técnica e faz da sequência de páginas uma sequência de planos comandada pelo leitor, ao deslizar o dedo sobre a tela. Partes da cena entram e saem de foco sugerindo o extracampo. $O$ texto acompanha todas as mudanças de planos e, se habilitada, a narração também. 

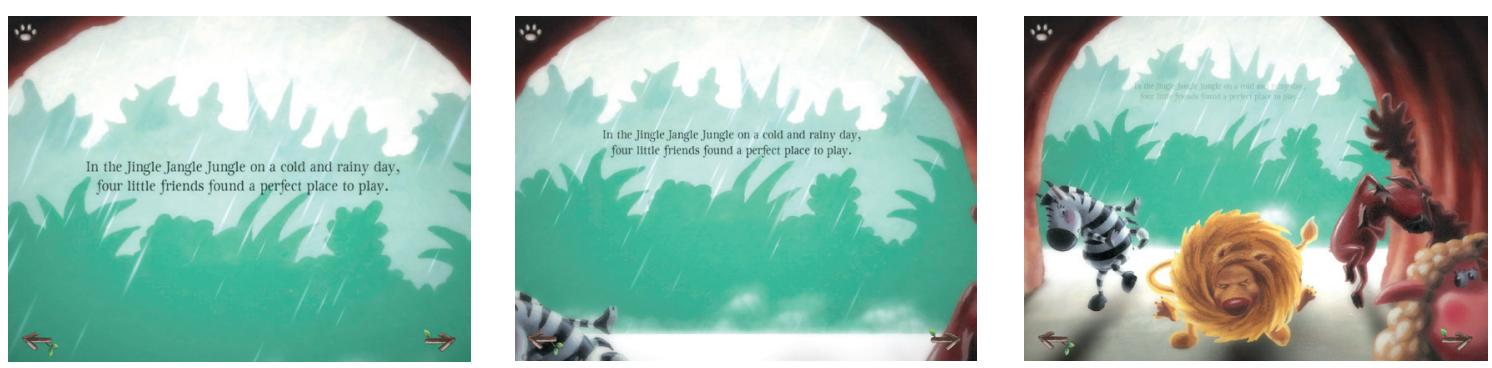

Figura 5 - Ebook The Very Cranky Bear. Sequência de planos.

\subsection{Montagem}

O livro ilustrado impresso pode usar a composição em página dupla para enriquecer a leitura se apropriando de maneira inteligente de sua organização material. A página dupla torna, assim, o encadeamento de uma página à outra mais fluido. Dessa forma, a montagem, no livro ilustrado, também se aproxima, em certos aspectos, da montagem cinematográfica. "Se a montagem, na sétima arte, consiste no encadeamento dos planos, no livro ilustrado trata-se de organizar a sucessão das páginas duplas." (id., p.78). A página dupla, quando transposta para o formato digital, sofre ajustes significativos (reduções, cortes, deformações, redução do corpo da fonte, entre outros) e o recurso de movimento de câmera, utilizado no livro The Very Cranky Bear (ver item 3.3), supre a função da página dupla mantendo o encadeamento dos planos com qualidade visual.
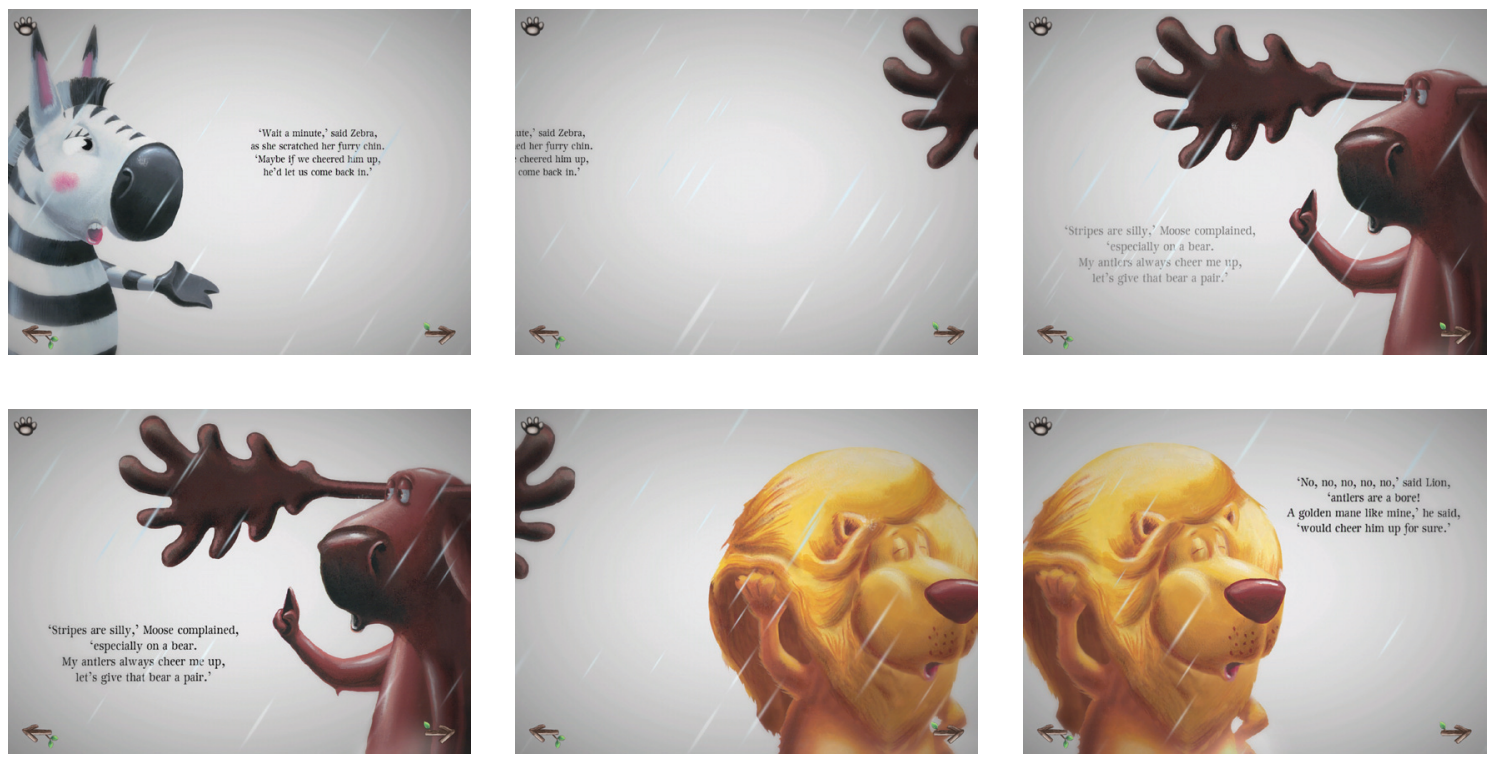

Figura 6 - Ebook The Very Cranky Bear. Recurso de "movimento de câmera".

\subsection{Junção}

"É uma sucessão de imagens articuladas, ligadas por um ou mais vínculos sejam eles icônicos, semânticos, plásticos, lógicos ou apenas técnicos.” (id., p.82). A organização de sequências narrativas exerce uma função de ligação, e essas articulações preveem mudanças de fundo, margem, vinhetas, entre outros. Há sempre um elemento que cumpre o papel de transição. Um ebook que apresenta toda a sua narrativa utilizando o recurso da junção é o Petting Zoo.

Lançado em 2013, Petting Zoo é um appbook sem texto e com ilustrações bemhumoradas de animais em diferentes situações ou desempenhando diferentes atividades. De layout fixo, oferece uma interação de simples assimilação, mas que evidencia o toque 
inteligente. A mudança de página se dá com o toque em uma seta localizada no canto inferior da tela que provoca uma metamorfose divertida de um animal em outro, ou uma transição dando início a um novo capítulo, ou seja, é uma junção que, ao utilizar os recursos oferecidos pelo suporte digital, torna-se animada.
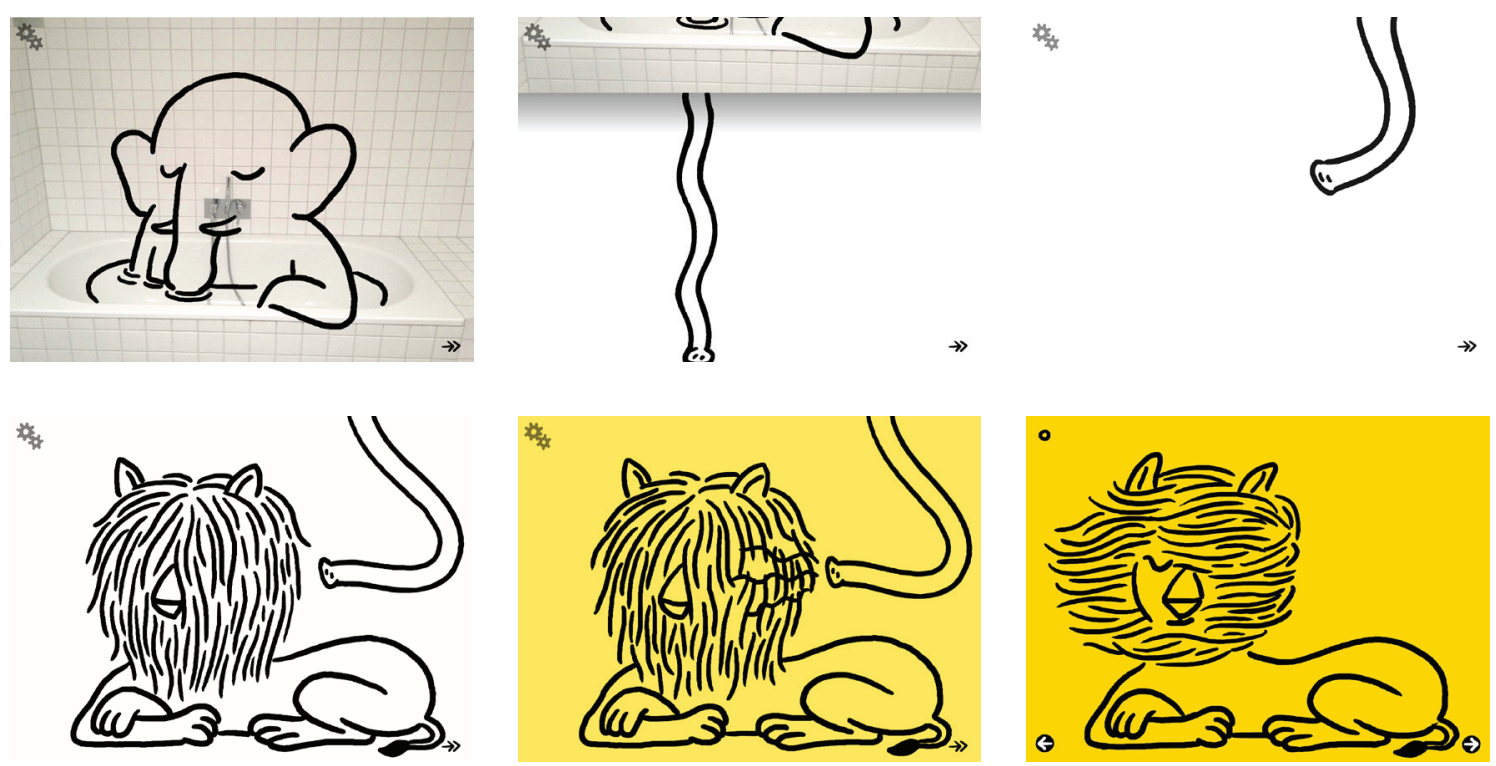

Figura 7 - Ebook Petting Zoo. Transição de um personagem a outro.

\section{CATEGORIAS REFERENTES À DIMENSÃO NARRATIVA DAS RELAÇÕES ENTRE TEXTO E IMAGEM}

Considerando a relação texto/imagem da narrativa, destacamos três aspectos indicados por Van der Linden: relação de redundância, relação de colaboração e relação de disjunção.

\subsection{Relação de redundância}

É uma relação que não produz nenhum sentido suplementar. Ambos, texto e imagem, remetem à mesma narrativa.

Um deles pode dizer mais que o outro. Por definição, conteúdos idênticos são impossíveis, já que texto e imagem pertencem a linguagens distintas. A redundância se refere à congruência do discurso, o que não impede, por exemplo, que a imagem forneça detalhes sobre o cenário ou desenvolva um discurso estético específico. (id., p.120)

É comum lermos ebooks com recursos interativos que apresentam esse mesmo tipo de relação, ou seja, o conteúdo da imagem coincidindo com o conteúdo verbal. Os recursos não levam a uma ampliação do sentido desse conteúdo. Mas, como a narrativa deve ser entendida em seu caráter simultaneamente verbal e visual, existem casos em que esse tipo de interatividade é bem-sucedida, como em Alice in Wonderland para iPad.

Esse ebook, lançado em 2010, mesmo ano de lançamento do iPad, foi um sucesso de crítica e de vendas ${ }^{4}$. Com layout fixo, a história de Alice é recontada e as ilustrações originais de John Tenniel são animadas e recebem cor.

4 Em abril de 2010, o ebook foi apresentado no Oprah Winfrey Show. 
Esta versão de Alice é visualmente estimulante e, apesar de os recursos interativos - que são praticamente os mesmos durante toda a história - não contribuírem para a narrativa, seduzem e prendem a atenção do leitor. Este é um exemplo de como a relação de redundância ganha nova dimensão quando articulada com a interação; ela contribui para enriquecimento da experiência de leitura, já que, como dissemos antes, a experiência de leitura é mais do que a decodificação do texto ou a recepção passiva do conteúdo verbal.
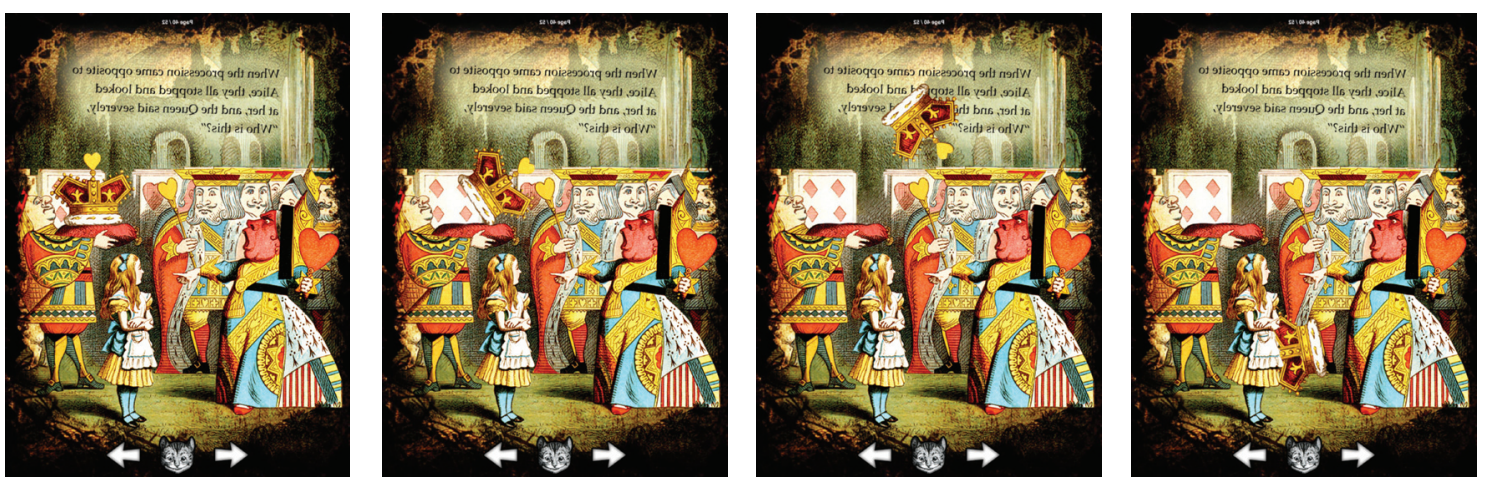

Figura 8 - Ebook Alice in Wonderland. Relação de redundância é redinamizada.

\subsection{Relação de colaboração}

Van der Linden prefere o termo "colaboração" a "complementariedade", pois melhor expressa a ideia de que texto e imagem trabalham tendo "em vista um sentido comum". A relação de colaboração

considera de que modo se combinam as forças e fraquezas de cada código e, articulados, texto e imagem constroem um único discurso. Numa relação de colaboração, o sentido não está nem na imagem nem no texto; ele emerge da relação entre os dois. (id., p.121)

Cada vez mais os ebooks estão sendo desenvolvidos de modo a utilizar esse tipo de relação. O recurso tecnológico entra na história para enriquecer a narrativa de uma maneira que não seria possível no livro impresso. A interatividade vai além da superficialidade e percebemos então um uso mais consciente da tecnologia.

Four Little Corners (ver subitem "associação", no item 3.1) é um ebook dirigido a uma criança muito nova, ainda com pouca experiência do mundo. Então, as ações representadas pelas animações são simples, podendo ser facilmente reconhecidas, e não existem detalhes sem correspondência no texto verbal. O ebook aproxima o leitor da narrativa pelo toque, pelo áudio e pelo movimento das imagens (os 3 sentidos; tato, audição e visão).

A cor é um elemento fundamental. Por exemplo, em uma das cenas, o Little Square quando se entristece deixa de ser verde-claro e passa a ser verde-escuro. O estilo visual do ebook dialoga com o texto, que é simples e sintético. Isso significa que o projeto gráfico foi bem definido; texto, ilustração e multimídias estão colaborando para o desenvolvimento da história.

A tipografia utilizada é simples, sem serifa e bold. Tem boa legibilidade e é sempre acompanhada por uma narração em áudio, mas o texto não é iluminado (highlight) de acordo com a voz da narração (reading aloud).

A interatividade proporcionada pela tecnologia ajuda e enriquece o desenvolvimento da narrativa. São ações simples que requerem recursos simples, 
mas que fazem a criança interferir no desenvolvimento da história. Por exemplo, no momento em que o quadrado tenta por si próprio mudar sua forma, as diferentes tentativas só acontecem após o toque na tela.
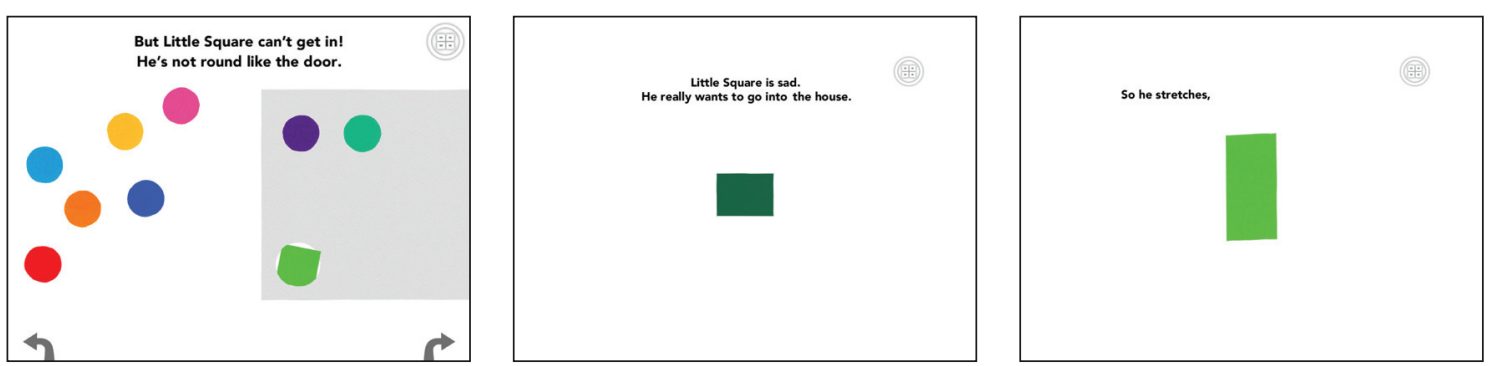

Figura 9 - Ebook Four Little Corners. As possibilidades interativas articuladas com texto e imagem.

\subsection{Relação de disjunção}

Essa relação é raramente encontrada nos livros ilustrados, apesar de criar um efeito interessante na narrativa. "A disjunção dos conteúdos pode assumir a forma de histórias ou narrações paralelas. Texto e imagem não entram em estrita contradição." (id., p.121)

Os ebooks que oferecem opções de games ou uma narrativa não linear podem se encaixar nessa categoria, e aqui apresentaremos dois tipos de equacionamento da relação de disjunção.

Jack and the Beanstalk é um exemplo de ebook que apresenta a opção de jogo. Vencedor do terceiro lugar no Bologna Ragazzi Digital Award de 2014, este ebook conta a clássica história do menino pobre que troca sua única vaca por um punhado de feijões mágicos. De layout fixo, o appbook apresenta jogos que fazem parte da narrativa. Jack, totalmente guiado pelo leitor, deve vencer os desafios para a história continuar. O ebook ainda oferece a seguinte possibilidade: ao clicar em uma aba localizada no canto superior direito, o leitor tem acesso direto ao jogos sem precisar ler a história.

São narrativas paralelas que se abrem de acordo com a exploração do leitor através do personagem principal. É interessante notar que todos os jogos estão intrinsecamente relacionados à história e contribuem para o desenvolvimento da narrativa.
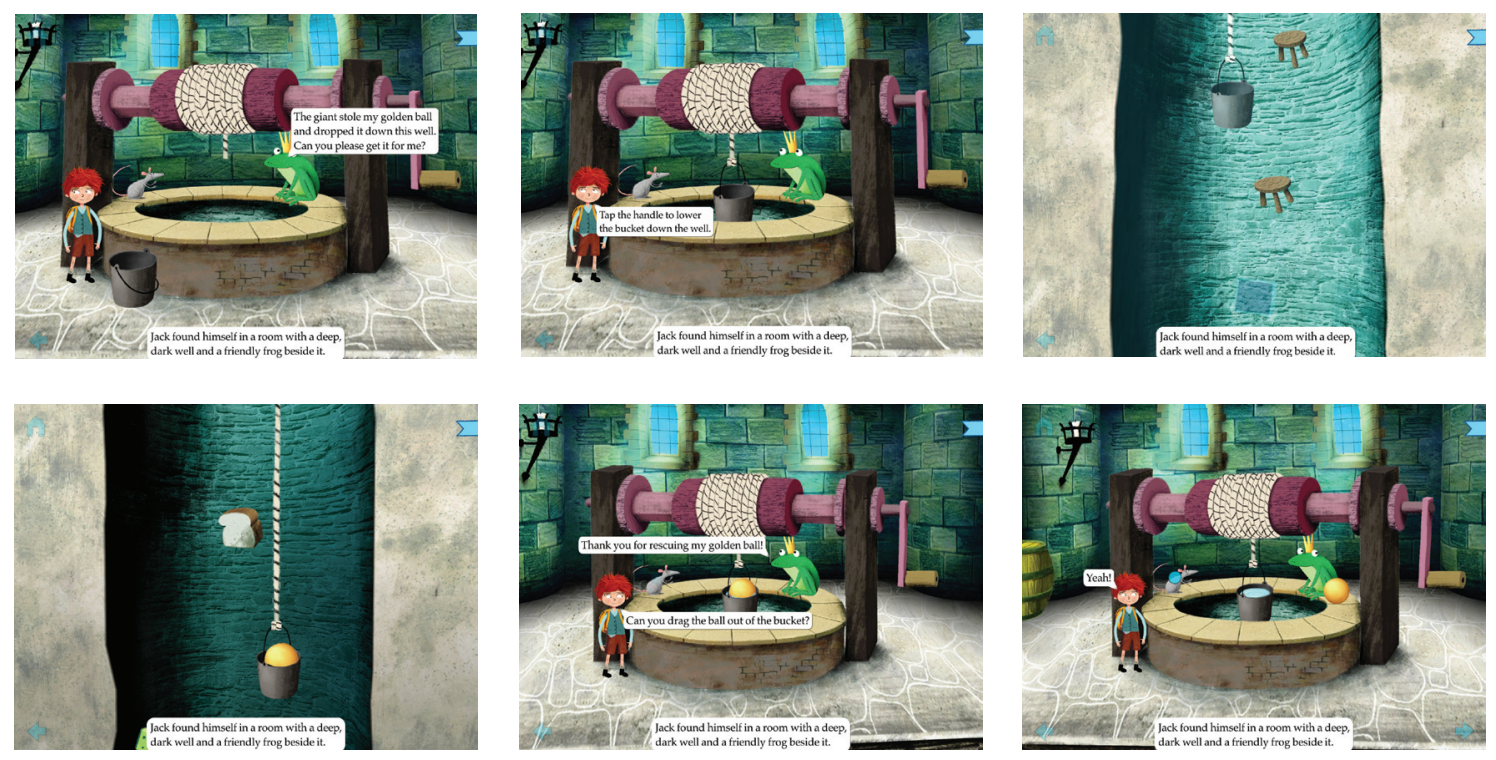

Figura 10 - Ebook Jack and the Beanstalk. Jogo contribuindo para o desenvolvimento da narrativa. 
Animais em movimento é um ebook definido por sua própria equipe realizadora como o "primeiro ebook para vivenciar com o corpo"; foi anunciado como o resultado prático de um estudo da receptividade ao formato digital, junto a crianças com dificuldades de comunicação (autistas, deficientes intelectuais e deficientes múltiplos) e aos profissionais que as atendem. É um projeto francês desenvolvido pela Signes de Sens, adaptado do livro-dvd homônimo publicado pela Conte sur tes Doigts.

O conceito do ebook é simples: propor uma maneira inédita e lúdica de ler, no tablet, que favoreça a atenção e a concentração. A criança pode escolher ver o animal em movimento, imitá-lo e aprender o seu nome na língua de sinais.

Este ebook foi pensado para ser lido com a família; apresenta vídeo, ilustrações e áudio. $\mathrm{O}$ ebook é separado em capítulos e cada capítulo é sobre um animal. Os vídeos mostram um ator que conta a história utilizando a técnica da mímica. A intenção é que, inspirada pela mímica do ator, a criança possa fazer a sua própria mímica e contar a mesma história para a sua família, ou inventar uma nova história. Assim, o jogo acontece fora do dispositivo. A criança interage com o ambiente e com a família e vivencia o livro com o corpo.
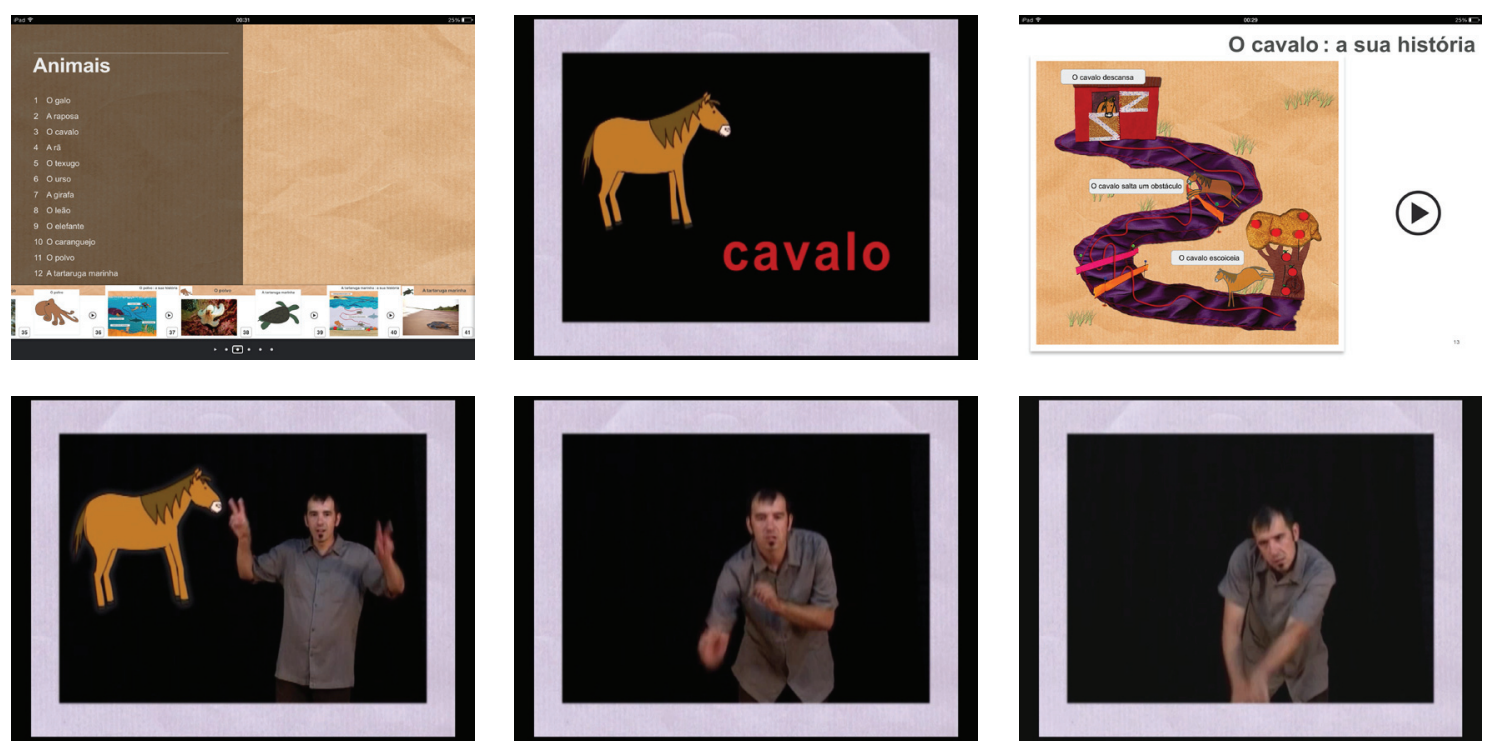

Figura 11 - Ebook Animais em movimento. Construção de histórias paralelas e interação com o ambiente.

\section{CONSIDERAÇÕES FINAIS}

Neste artigo, nossa intenção não foi a de buscar análises definitivas, e sim a de caracterizar aspectos que contribuam para o processo de conhecimento do ebook infantil. É importante salientar que este breve estudo de como a interação pode redesenhar categorias gráficas próprias da tradição do livro impresso se baseia em uma estratégia específica de investigação. Outros encaminhamentos de pesquisa - privilegiando, por exemplo, os recursos tecnológicos, a recepção dos livros pelas crianças, a metodologia específica de projeto, entre outros aspectos - certamente levarão a outras dimensões de compreensão do tema.

Segundo as potencialidades da metodologia proposta, a investigação a partir de categorias do livro ilustrado pode ser aprofundada tanto partindo do impresso para o interativo - conforme o artigo apresenta -, quanto identificando especificidades do artefato digital e buscando correspondências no âmbito do impresso - considerando, inclusive, o pressuposto de que elas podem não ser encontradas. 
Uma segunda consideração sobre os resultados diz respeito a um cuidado epistemológico quanto à provisoriedade dos resultados, pois o desenvolvimento do ebook infantil ainda não está consolidado, estando ainda aberto a novos equacionamentos tecnológicos.

O que esta pesquisa e os artigos consultados deixam claro é que, ao passo que a produção de ebooks infantis cresce e amadurece, seu entendimento tende a tornarse mais claro. Depreende-se disso que o investimento em pesquisa e produção por parte das editoras é essencial para o desenvolvimento do mercado do ebook infantil. $\mathrm{E}$, paralelamente, a pesquisa acadêmica deve acompanhar o desenvolvimento desse processo. 


\section{REFERÊNCIAS}

Atomic Antelope. (2010). Alice in Wonderland (versão 3.1) [aplicativo para iPad]. Adquirido em http://itunes.apple.com.br

Conte sur tes doigts. (2013). Animais em Movimento (versão 1.0). [aplicativo para iPad]. Adquirido em http://itunes.apple.com.br

De DADA Company. (2013). Four Little Corners (versão 1.1) [aplicativo para iPad]. Adquirido em http://itunes.apple.com.br

Fox \& Sheep. (2013). Petting Zoo (versão 1.3). [aplicativo para iPad]. Adquirido em http:// itunes.apple.com.br

Light Publications. (2013). Cinderella Spinderella (versão 1). [aplicativo para iPad]. Adquirido em http://itunes.apple.com.br

Martin Hughes. (2012). Monster's Socks (versão 1.03) [aplicativo para iPad]. Adquirido em http://itunes.apple.com.br

Nosy Crow. (2014). Jack and the Beanstalk (versão 1.0.1). [aplicativo para iPad]. Adquirido em http://itunes.apple.com.br

Simon \& Schuster Books for Young Readers. (2013). What does the Fox Say? (versão 1) [aplicativo para iPad]. Adquirido em http://itunes.apple.com.br

We Are Wheelbarrow. (2012). The Very Cranky Bear (versão 1.7). [aplicativo para iPad]. Adquirido em http://itunes.apple.com.br

HENDEL, Richard; tradução Geraldo Gerson de Souza e Lúcio Manfredi. 0 design do Livro. 2ª edição. São Paulo: Ateliê Editorial, 2003.

LINDEN, Sophie van der; tradução Dorrothée de Bruchard. Para Ler o Livro llustrado. $1^{\text {a }}$ edição. São Paulo: Cosacnaify, 2011.

OLIVEIRA, Danusa. A profissionalização de designers de ebooks no Brasil: um olhar sobre iniciativas nacionais. In: 2을 CONGRESSO INTERNACIONAL DO LIVRO DIGITAL. SÃO PAULO/ SÃO PAULO, 7.2011.

YOKOTA, junko. TALE, William H. (2014, March). Picture Books and the Digital World: Educators Making Informed Choices. In: CInternational Reading Association and the authors. The Reading Teacher, March 2014, vol. 34, nr. 6 